Article

\title{
On Waxworks Considered as One of the Hyperreal Arts: Exhibiting Jack the Ripper and His Victims
}

\author{
Lucyna Krawczyk-Żywko \\ Institute of English Studies, University of Warsaw, 00-681 Warsaw, Poland; lucyna.krawczyk@uw.edu.pl \\ Received: 30 April 2018; Accepted: 24 May 2018; Published: 30 May 2018

\begin{abstract}
The article discusses one of the tropes present in the representations of the Whitechapel killer: the waxworks of either the killer or his victims. These images were shaped by contemporary attitudes: from sensationalism in 1888, through the developing myth and business of 'Jack the Ripper,' to the beginnings of attention being paid to his victims. Examined are tableaus created from 1888 to current times, both physical and fictional twenty- and twenty-first-century texts encompassing various media, all of which may be located within the Baudrillardian realm of simulation. What they demonstrate is that the mythical killer keeps overshadowing his victims, who in this part of the Ripper mythos remain to a certain extent as dehumanised and voiceless as when they were actually killed.
\end{abstract}

Keywords: Jack the Ripper; representation; simulacrum; victims; waxworks

Waxworks was one of the manifestations of the nineteenth-century fascination with the nascent cult and culture of celebrities, a culture that in the twentieth century incorporated serial killers as well (Schmid 2006). In the nineteenth century, visiting exhibitions of wax figures which included infamous criminals was a means of substituting for the 'lost pleasure' of public hangings (Pamela Pilbeam qtd. in Worsley [2013] 2014, p. 58). The association of representations of villains with this medium became so close that its dictionary definition includes the following usage as an example: "no waxworks is complete without its chamber of horrors" (Waxwork n.dat.). It would be equally difficult to argue with a parallel statement that no chamber of horrors is complete without Jack the Ripper. This article examines various wax representations of him and his victims, with the term 'waxworks' used to denote not only dummies put on show in the Victorian times but also the ones on display now, as well as their various transmediations, group or individual, on page and screen. Since there is no known model to base his wax likeness on, any representation of the infamous Jack poses a number of questions about the status of the Whitechapel killer and his victims. Together with Vlad the Impaler, Elizabeth Batory, Atilla the Hun, Rasputin, and Billy the Kid, a victimless seven-inch Jack the Ripper figurine represents a historic 'face of madness' (McFarlane's Monsters series 3: Six Faces of Madness 2004). This is one of numerous attempts to give the anonymous, faceless killer some form and shape: evil that can be named and seen seems less malevolent, more manageable. This sense of control is, however, false, since any representation of the Whitechapel killer has no genuine model and can only be described using the Baudrillardian concepts of simulacrum and hyperreality.

Jean Baudrillard described hyperrealism as 'the meticulous reduplication of the real, preferably through another, reproductive medium'; with each transmediality, the real is 'volatilized', but, at the same time, 'reinforced', eventually becoming 'reality for its own sake ... the hyperreal' (Baudrillard [1976] 1988, p. 144, emphasis original). However, in the case of the Whitechapel killer there is no 'real' - there is only 'simulation': 'the generation by models of a real without origin or reality: a hyperreal' (Baudrillard [1981] 1988, p. 166). What is known about him (or her) stems from sensational press reports which were informed by Gothic imagery and the fear of the other. The creation of the 
image of Jack the Ripper, including his wax likeness, complete with his (stereo)typical signifiers-long knife, top hat, black bag, black overcoat-stems from descriptions by people claiming to have seen him, and its development is parallel to the steps Baudrillard assigned to the creation of a simulacrum: ' 1 It is the reflection of a basic reality' (the witnesses' words), ' 2 It masks and perverts a basic reality' (sensational press reports), '3 It masks the absence of a basic reality' (reproductions of images), '4 It bears no relation to any reality whatever: it is its own pure simulacrum' (production of waxworks) (Baudrillard [1981] 1988, p. 170, emphasis original). Accordingly, Dan Laughey states that the Ripper 'has become a Baudrillardian simulation' and 'is hyperreal' (Laughey 2013, p. 95), and the following paragraphs will discuss twenty- and twenty-first-century texts encompassing various media-novels, short stories, films and TV series, computer and virtual reality games, and museum exhibitions-which serve as further evidence that figures of Jack not only do not bring us any closer to revealing the identity of the killer or discovering the reality of this figure, but speed it along its path towards the mythical, while at the same time making the very real victims of the notorious murderer less real and less fleshed-out.

Publications addressing depictions of the Ripper in wax (Aliffe 2002; Woods and Baddeley 2009) seem to develop the list of titles provided under the label the 'waxwork motif' offered in Jack the Ripper. His Life and Crimes in Popular Entertainment (Coville and Lucanio [1999] 2008, pp. 58-59). A notable exception is the Ripperologist article, 'Whitechapel's Wax Chamber of Horrors, 1888' (2013), in which Mike Hawley presents the then exhibition of the images of the Ripper victims and the outrage it caused. Mark Jones describes the waxwork theme as 'a minor strand in Ripper representations' (Jones 2017, p. 171), yet the very fact of its continuous presence over the last thirteen decades deserves consideration. The present article aims to examine the 1888 instances of depicting both the killer and the victims in wax in the context of the sensationalism and curiosity about various anomalies permeating the era, as well as their later screen, print, and museum adaptations and appropriations in the context of the Ripper's cultural afterlife. Unlike other neo-Victorian re-imaginings, which 'seek to return the murderer to reality by narrating motivation' (Maier 2012, p. 198), the waxwork theme ignores historicity in favour of symbolism. It is my contention that its particular stages aptly reflect the changes in the cultural significance of the killer, but generally fail to address the imbalance between his and his victims' representations.

Calling the nineteenth century a golden age of waxworks would not be an exaggeration. What became the best-known museum of wax figures in the world started with Marie Tussaud's thirty figures exhibited in London in 1802. Nine decades later, one of its infamous exhibits-Mrs Pearcey-attracted over thirty thousand visitors on a single day-Boxing Day; this seems to confirm Lucy Worsley's conclusion that the best form of spending free time for lower classes was being 'face-to-face with murderers' (Worsley [2013] 2014, p. 62). The Victorians were well aware of the marketing potential notorious figures offered to any entertainment and news business. The Star newspaper, launched in January 1888, would not have achieved its status or popularity had it not been for its sensational reporting of the Whitechapel murders of that year. It was not possible for Madame Tussaud's to capitalise on the case by including Jack the Ripper among its waxen figures due to its strict policy on adhering to the original: there was no original to model on. For many years, its only references to the figure of the mysterious murderer had been other killers: George Chapman, Thomas Neill Cream, Frederick Bailey Deeming — suspects at various stages of the development of the Ripper myth —and Florence Maybrick, whose husband is also often listed as a suspect (Woods and Baddeley 2009, p. 170). Other Victorian entrepreneurs, however, were free from such qualms and exhibited not only the seemingly faceless Whitechapel killer but also the images of the bodies of his victims.

The shockingly detailed and graphic descriptions of the injuries of the Ripper victims disseminated by the press, which probably served as the basis for their models in wax, cannot be treated merely as a medical report of post-mortem examinations. To contemporary commentators their bodies were 'reminiscent of "those horrible wax anatomical specimens" on display in medical museums and in the windows of anatomical shops' (Walkowitz 1992, p. 199). Both Hawley (2013) and Worsley [2013] 
(2014) place their discussions of Victorian waxworks in the context of 'Venuses'-models of female bodies displayed in anatomical museums, which exposed internal organs, including reproductive ones. However, if some of these models 'were venerated as beautiful and even erotic objects' (Worsley [2013] 2014, p. 55), the Whitechapel victims were compared to 'slaughtered animals' and 'dissected cadavers' that seems to better reflect the prevailing mood. Individually, the victims and their bodies ceased to matter; collectively, they became 'the mounting array of the "grotesque," mutilated corpses' (Walkowitz 1992, p. 198). When photographed and '[d]epersonalised in sepia and white, the women became static dissections of the Ripper's deviant psyche to be studied for clues to his identity, not their individual personae' (Maier 2012, p. 202). Similarly, waxworks representing those women mattered so far as they mirrored the wounds inflicted by the mysterious killer.

Already in August 1888 people interested in following the bloody trail of the Whitechapel killer could admire his latest 'work' in the form of wax figures of his victims at 106 Whitechapel Road, with exhibits being added following each murder (Hawley 2013). They formed a part of a relatively typical display which included various 'celebrities' and a chamber of horrors, whose proprietor, Thomas Barry, did not refrain from using a fair amount of red paint to exploit the most recent victim. As noted by Helen Davies, the 'victimisation' of the women killed during the Autumn of Terror 'continue[d] with posthumous objectification and exhibition' (Davies 2015, p. 160). They were no longer working as prostitutes, but new procurers were profiting from displaying their wax likenesses, an equivalent to the continuation of the selling of their exposed bodies to anyone willing to pay the admission price. An interesting commentary on the consumers of wax exhibits of the victims of Jack the Ripper comes from a seemingly unlikely source-a man who himself was a freakshow attraction, Joseph Merrick, the so-called 'Elephant Man'. He noted that the people interested in seeing such ghastly displays wore black silk hats, white scarves, and parasols (Davies 2015, p. 159)—apparent signifiers of a class that rarely visited Whitechapel, accessories usually spotted among the 'slummers'. Waxworks were used to satisfy the curiosity and morbid needs of the audience of the Whitechapel murder series, but also became a kind of canvas on which the viewers could trace the macabre progress of the 'artist'.

Thomas Barry and his daughter, Mrs Roberts, would probably have continued their business undisturbed had it not been for the form of advertising they chose. The front window of their museum displayed pictures of the exhibits, 'the poor victims who have been so brutally murdered of late' (Hawley 2013, p. 19). As reported by contemporary newspapers, 'One picture showed six women lying down injured and covered in blood, and with their clothes disturbed,' and within five days of the murder of Annie Chapman, a wax likeness of her body was added to the collection and advertised with another distressing picture (Hawley 2013, p. 19). Even if in reality, the waxworks within were 'sadly mutilated figures that have done duty on many previous occasions' which were now treated with 'a few streaks of red paint,' as reported in East London Observer two days later (Hawley 2013, p. 20); at that particular moment they were representing women who lived in the area and whose fate was not merely a sensational piece of gossip to those who knew them. The reaction of the locals, who were threatening to destroy the picture and were dispersed by the police, testifies to that. Thomas Barry had to remove the picture and, in the end, was convicted for 'being a nuisance in Whitechapel Road' (Hawley 2013, p. 25). He was using the images of the victims to attract customers to his collection which included many notorious characters, organised in tableaus recreating the very act of committing murder, or execution of the murderer. Although he relied on representing in wax what everyone could read in the press, the reaction of the East Enders made him turn to exhibiting an apparently less disturbing element of the Whitechapel horror-an effigy of Jack the Ripper.

London was not the only city where a representation of the Whitechapel killer could have been seen. On November 17, 1888, the Star reported that a wax figure of the Ripper on display in Liverpool was damaged by a Canadian tourist, who was later arrested and fined (Curtis 2001, p. 211), but the waxworks business specialising in horrors was too lucrative to allow itself to be in any way hampered by such events. In her account of the Victorian fascination with crime, Judith Flanders notes that already by the spring of 1889 , mere months after the last murder attributed to the Whitechapel killer, 
'Jack the Ripper exhibitions were a commercial proposition' and quotes two advertisements relating to that. One is from a provider for "The Wax Head of "Jack the Ripper", carefully Modelled from Sketches published in the "Daily Telegraph", Furnished by witnesses who had actually seen him, also a Wax Head of Mary Jeanette [sic] Kelly, hi[s] last victim', and the other from a waxworks in Cardiff declaring an intention 'to buy a Set of Jack the Ripper Victims' (Flanders 2011, p. 452).

What emerges from the 1888 and 1889 reports is that whereas the wax images of the victims 'stopped' at the second stage of simulacra, reflecting and perverting reality, the wax images of the killer went a step further and masked the absence of the original model (Baudrillard [1981] 1988, p. 170). What is interesting, when the wax version of the killer started to be represented in popular culture at the beginning of the twentieth century, it was only the killer's simulacrum that continued its development; his victims were put to rest, at least for a few decades.

As suggested by Denis Meikle, the text that might have influenced two earliest cinematic depictions of the waxwork motif, Farmer Spudd and His Missus Take a Trip to Town (1915) and Waxworks (1924), was The Lodger by Marie Belloc Lowndes (Meikle 2002, p. 48), first published as a short story (1911) and then as a novel (1913). Towards the end of the plot, its Jack the Ripper character, Mr Sleuth/The 'Avenger', suggests to Mrs Bunting, his landlady, and Daisy, her stepdaughter, a visit to Madame Tussaud's to celebrate Daisy's eighteenth birthday. The venue has positive connotations to Mrs Bunting, as it was the place where she used to spend a lot of her free time with her husband-to-be. The lodger has never been there, and his first impression is negative: 'The presence of those curious, still, waxen figures which suggest so strangely death in life, seemed to surprise and affright him' (Lowndes [1913] 2015, p. 271). Still, the girl's excitement about going into the Chamber of Horrors seems infectious, and they are about to enter 'the curious, vault-like chamber where waxen effigies of dead criminals stand grouped in wooden docks' (Lowndes [1913] 2015, p. 272). What prevents them from going in is the presence of important visitors inside, among them the Commissioner of the London Police and the chief of the Paris Police. The former is overheard saying he is on the verge of catching the perpetrator of the latest series of murders and he knows what the man looks like. Suspecting his landlady of betrayal, Mr Sleuth excuses himself by saying he is feeling ill and exits the building, never to come back. ${ }^{1}$

Fictional representations of Jack the Ripper as a wax figure reflect the change in the perception of him as a more and more mythical being: from a real threat in 1888 to an oneiric presence on the silent screen. The aforementioned Farmer Spudd and His Missus Take a Trip to Town (1915) was a short movie about a couple visiting the Chamber of Horrors, falling asleep there, and dreaming about the exhibits coming to life, one of them being Jack (Aliffe 2002). His next screen appearance is in the German Expressionist film Waxworks (1924), originally Das Wachsfigurenkabinett, directed by Paul Leni. Screen captions inform us that the Jack the Ripper figure, here labelled Spring Heeled Jack, is 'the most amazing character of all times', but also 'the notorious character [who] pounced suddenly and silently upon his victims'. He is one of the figures that need appealing advertisements, 'startling tales' that would attract visitors to the fun fair where the exhibition is set; the other two are Caliph Haroun-al-Raschid and Tsar Ivan the Terrible. The tales about the historic, or real, characters written

1 There was no possibility for Mr Sleuth to face his wax likeness in Madame Tussaud's in The Lodger, but Scotland Yard's Museum, another 'regular Chamber of 'Orrors,' is mentioned in the text (Lowndes [1913] 2015, p. 91). Man in the Attic (1953), one of the screen adaptations of Lowndes's novel, addresses the question of how the killer might react when confronted with exhibits of his deeds. Unlike in the novel, where Scotland Yard's Black Museum is visited by Daisy and Mr Bunting, courtesy of PC Joe Chandler, in the film adaptation we follow Jack the Ripper himself admiring his 'work'. An interesting instance of a rewritten Victorian villain visiting Madame Tussaud's and commenting on his representation is Cole Haddon and M.S. Corley's comic book The Strange Case of Mr. Hyde (Haddon and Corley 2012). Hyde, looking nothing like the monster he is supposed to be, notices a hideous wax figure-a tableau depicting the incident with the girl, the first instance when the readers meet Hyde in Stevenson's novel-and says: 'Oh dear, this isn't right. There was no pram' (p. 71). A similar impression is expressed in The Autobiography of Jack the Ripper, when the eponymous killer comments on Paul Leni's Waxworks, a film he believes to be 'technically perfect': 'But as regards the episode of Jack the Ripper, I am able to state, from definite knowledge, that it bore not the slightest resemblance either in person, scene or action to the reality; of course, I should have marvelled had it been otherwise' (Carnac 2012, p. 281). 
by the Poet (William Dieterle) reflect his interest in the daughter of the waxworks proprietor, and are presented to the viewer in the form of cinematic stories. It is only the more legendary, or hyperreal, Jack the Ripper (Werner Krauss) that is depicted in a dream sequence about an animated wax figure. Described as the most expressionistic episode of Waxworks (Eisner [1974] 2011, p. 76), the final and the shortest sequence (approximately six minutes out of almost two hours of the running time) presents the waxwork as not only moving, but following the Poet and the Daughter. The close-ups on his eyes create an impression that the infamous killer is looking straight at the viewer. The surreal zeotropic background increases the feeling of unease, culminating when the approaching figure itself is multiplied-it seems there is no escaping him. The Poet is stabbed with the knife, an indispensable Ripper accessory, and probably the only (stereo)typical Ripper signifier modern audience would recognise, since the figure is dressed in a double-breasted long coat accessorised with a long white scarf and a homburg hat. If it were not for those eyes and stealthy steps combined with the initial uncertainty whether the figure is actually alive, this representation would not seem that sinister or scary. The nightmarish sequence ends, the knife turns out to be the only weapon the Poet has: his own pen; everyone, including the viewer, is safe. The hyperreality, after all, comprises of images and signs, not of actual objects.

Before discussing other screen representations of Jack in wax, let us turn to the text that introduces the theme of a special relationship between the person owning and/or running the waxworks and the figures. Robert Arthur's ' . . said Jack the Ripper' is a 1957 short story which was included by Alfred Hitchcock in his collection of sixteen tales of terror published a few years later. Like waxworks depicted by Leni, Pop Dillon's Chamber of Horrors, known as Waxworks Museum Supreme, is located in an amusement park. Dillon has a habit of talking to his figures, who, apparently, talk back:

Pop was always willing to chat when one of his wax figures seemed in the mood, and he had had a number of interesting conversations with some of them, such as the ones he had with Jack the Ripper, who was naturally boastful. Others, though, never spoke a word-they were the silent types. Pop never tried to force them to talk—even a wax dummy had a right to privacy, he figured. (Arthur [1957] 1973, p. 90).

The other boastful type and a good talker is Billy the Kid, while Jesse James is the only silent one (Arthur [1957] 1973, p. 93). The story revolves around the latest tableau depicting the execution of one Burke Morgan, who unexpectedly escapes and hides among Dillon's wax figures. The Ripper values Morgan's 'work' and describes him as 'a very artful dodger' (Arthur [1957] 1973, p. 94), yet his loyalty to Dillon and admiration for his skills are stronger. Moreover, Jack is a proper team worker-when Morgan dies and a new voice is added to Pop's figures, one boasting about being the greatest attraction, the Ripper immediately reacts:

Let him talk all he wants, Jack said. Just don't answer him and he'll get tired of being left out. There's no point in being concerned over who draws the crowds, because what's good for one of us is good for all of us. Why, think what would happen if Pop ever had to go out of business. We'd be sold, melted down—killed. (Arthur [1957] 1973, p. 102, emphasis original).

Such a manifestation of solidarity coming from the most notorious murderer may seem surprising, however, it may also be read as an expression of the status of the Ripper at the time-an uncaught murderer, true, but when shaped as a wax figure, merely one of many infamous figures. What further reduces his significance as a key attraction of the museum is the medium-a short story which does not describe his appearance. Paradoxically, it highlights the importance of his words and makes this text probably the only positive representation of Jack the Ripper not only as a wax figure, but as a character. What enforces this positive reading is the lack of his victims: omitted, they cannot testify to his horrible deeds, and their absence masks the 1888 reality. This Ripper is no longer the Whitechapel killer but a fun fair attraction bearing little relation to 'himself', his own simulacrum. Whether the events described in the story are manifestations of some supernatural agency, a product of the main character's imagination, or possibly even deranged mind, is for the reader to decide. 
The motif of a Jack the Ripper waxwork in danger of being 'killed', whilst also being used to satisfy and conceal one's murderous instincts by presenting the figure as seemingly coming to life, is used in two screen representations: 'The New Exhibit' (1963), an episode of The Twilight Zone TV series, and Terror in the Wax Museum (1973), a horror/mystery movie. Although both depict the Ripper as one of many exhibits, his status seems extraordinary. 'The New Exhibit' Jack is described by Martin Senescu (Martin Balsam), the curator of Ferguson's Wax Museum, as 'another soul in torment ... immortalised in wax, remembered as you and I will never be'. What distinguishes him from other figures is a hidden mechanism - when the tour of the Murderers Row comes to an end and Jack's story has been presented, the figure's hand holding the knife, described as the one that was used to kill his victims, swings unexpectedly, scaring and exciting visitors. Unlike some exhibits there, which are organised into tableaus representing the acts of murders, the Ripper (David Bond) stands alone. His clothes seem inconspicuous, yet the scarf around his neck is reminiscent of Leni's depiction and the black bag denotes evil intentions, an impression strengthened by the dark eyes and sinister grin. His victims are merely mentioned, described by the curator as 'pathetic drabs'. When Senescu decides to save the five infamous figures from uncertain fate after Fergusson is forced to sell the museum by placing them in his basement, Jack is the one that attracts his closest attention. And Jack is the one that commits the first murder, at least so it seems.

Similar seniority is attributed to the wax figure of the Ripper in Terror in the Wax Museum. Its very opening is suggestive of a standard Ripper-esque scene: a horse-driven cab moves along an almost empty, gas-lit street, and when a police officer appears the viewers seem already prepared to hear the scream of another victim. The plot is set ten years after the last Ripper murder, and his wax likeness is the main attraction of Duppree's Wax Museum and Chamber of Horrors, advertised as 'London's very own Jack the Ripper'. It is introduced as an uncanny presence-when MrDuppree is thinking about selling his establishment, Jack looks 'as if he knew what [Duppree is] contemplating'. Jack is the first figure to attack the proprietor, first verbally and then physically, in what turns out to be Duppree's bad dream. What is more, it is Jack's knife that is used to eventually kill him. As suggested by one of the characters, the real Ripper, who was never caught, might have 'came out of the retirement because he didn't like the way he looked here in wax'. Despite, or because of, such suggestions, Jack continues to attract visitors to the museum: 'Show us the bloody Ripper. We want the Ripper', they demand. And thus, the notoriety of the cleanshaven figure in a white shirt, black jacket, coat, and hat, holding the deadly knife and apparently seen at new crime scenes continues.

'The New Exhibit' posits five infamous killers in the category of would-be victims, exhibits in danger and in need of rescue, substituting the five original/real victims. Similar to Terror in the Wax Museum, it clears the figure of Jack of the possibility of being possessed by or being an incarnation of the 1888 Ripper, and capitalises on its status of a serial killer celebrity. While these two screen depictions present curators of waxworks whose interest in the infamous killers is bordering on obsession-one is suspected of impersonating the killer, the other is projecting his own murders on them-the open question remains as to what extent they may be reflecting the viewers' fascination with the Whitechapel murderer.

The titles discussed so far, especially the screen ones, rely on the concept of the uncanny (Cf. Smith 2016, p. 29; Jones 2017, p. 171) to unsettle the audience, but also, like any corporeal depiction of Jack the Ripper, force them to suspend their disbelief while looking at the likeness of someone whose face will most probably remain unknown. And since the easiest way to tame fear of the unknown is to ridicule it, a lighter form of representing the wax motif can also be found. 'House of Max' (1970) is the title of two episodes of an American spoof TV series Get Smart created by Mel Brooks, in which Maxwell Smart, an American, and his partner, Agent 99, cooperate with Chief Inspector Sparrow of Scotland Yard to solve a dozen Jack-the-Ripper-style murders committed in contemporary foggy London. When a suspicious man (George Sawaya) lurking around Agent 99 in Hyde Park is shot by Smart, there are no doubts as to his identity: black coat and top hat combined with a knife unequivocally signify Jack the Ripper, or, as a medical report confirms, his wax dummy. An inspection of three museums reveals 
that one, Duval's Cave of Wax, is missing the figure. This is confirmed not by a name tag next to an empty space, but by an incomplete tableau: a depiction of a solitary screaming woman. It could have gone unnoticed if Duval did not decide to stand in for the missing Ripper and, equipped with a knife, commence a mock attack on the agents. The proprietor turns out to be a genius when it comes to creating wax likenesses and a (mad) scientist in one-his primary occupation seems injecting figures with a life-giving serum, which also gives him complete control over the figure, and sending them to kill people.

'House of Max' is the first twentieth century title discussed here to include the wax likeness of a victim of Jack the Ripper. She seems presentable-dressed in a long purple skirt, black blouse, black hat with a white feather-with only a boa shawl that may be an indication of her profession; that, and the very presence of a solitary screaming woman in a wax museum specialising in fictional and historic villains. A cursory glance may suggest that this is a rather decent representation of the prospective victim, especially when compared with the real wax depictions from 1888; on the other hand, her appearance masks the everyday reality of the East End women who were forced to turn to prostitution as a way of earning not even a living, but a few pennies. Moreover, her part is comparable to other cinematic Ripper victims from the turn of the sixties and seventies, who were supposed to look pretty, seductive even, and scream - though this one cannot be heard. She is anonymous, and her main task is to reveal the absence of Jack the Ripper.

Waxwork (1998) and Waxwork II: Lost in Time (1992), both directed by Anthony Hickox, are preoccupied neither with Jack the Ripper, nor his victims, who yet again are used merely as clues to the identity of the figure. His animated tableau in the former and scene in the latter take very little screen time. In the first movie, he is overshadowed by a werewolf, a vampire, the Phantom of the Opera, zombies, and Marquise de Sade. Depicted as a moustachioed villain in a colourful attire comprising of a houndstooth jacket, checked coat, cravat and top hat-straight out of a Victorian melodrama, with the knife and the prostitute as the only proper indications of his identity-he becomes alive together with his victim, sporting a colourful dress and bright red lips. Together with numerous other waxworks, they attack the protagonists in the final scene, and the Ripper meets his end at the hand of a woman-Sarah, the main female character-who kills him with a blade much longer than Jack's knife. The sequel also positions the infamous killer and his victim among other villains and monsters, including aliens, zombies, Mr Hyde, Nosferatu, and Godzilla, who form a sequence of time-travelling episodes of kaleidoscopic dimensions. This time, however, since all the scenes take place not in waxworks but their 'original' time and place, it is the stereotypical cinematographic setting comprising of a cobbled street in London docks and a foggy evening that introduces the viewers to the Ripper. His identity is confirmed by further stereotypical elements of his attire, such as the black cloak, top hat, and bag, and an altogether untypical razor. Since the depicted scene is an attack on a prostitute, the screaming victim prompts some vaguely chivalric response in the main character, who is otherwise engaged in fighting for his life throughout all the time-travelling scenes: he knocks the razor out, kicks the Ripper, and disappears into another time and space. What is supposed to be a re-enactment of a Whitechapel murder scene is not only a recreation of a few already well-established Ripperan motifs (the killer's appearance, his 'toff' or mad doctor identity), but also another hyperreal scene grounded in the cultural afterlife, or the mythical 'reality' of the mysterious murderer.

The Waxwork sequel's setting and time-changing mood is the premise of a computer game of the same year. Waxworks (1992), a product of Accolade Inc. and Horror Soft Ltd., suggests that the gaming industry has learnt its lesson from a few years earlier, when the shocking graphics of the victims in the Jack the Ripper computer game (1987) caused very strong reactions (Begg and Bennett 2013, p. 253). Here the wax tableau of the killer and his victim is reminiscent of the cinematic depictions in 'The House of Max' and Waxwork: a prospective victim—this time almost fainting, not screaming-on the left, the gentlemen-like killer equipped with the knife on the right. Again, the Ripper segment is one of a series, the three others being an Egyptian princess entombed, a mutant plant in a mine, and zombies in a graveyard. The waxworks serve as time portals, worlds to be entered with the help of powerful 
magic in order to find and kill 'the most evil of all the twins that have been born to past generations in our family' and thus remove a witch's ancient curse (Waxworks 1992). The change from reception to interaction, which characterises such immersive media, includes the player character being accused of being the Ripper, fleeing from vigilantes, angry mobs or police, being arrested, and even watching one's avatar being hanged. The objective of the game is to collect useful objects and information and eventually kill the Ripper, which, being a time-travelling experience, would explain his disappearance and why the murders came to such an abrupt end. The final confrontation is a swordstick versus knife duel with a masked man in dark clothes, top hat, and carrying a medical bag. Even if the player character's throat is slashed, the game may continue until the Ripper, the evil twin, is killed-the medium-specific simulation of the encounter(s) guarantees that.

Despite being objectified and marginalised on screen, the victims were brought into focus in reality around the centenary of the Whitechapel murders. To a large extent, it was connected with the protests against various forms of centennial celebrations planned, for example, by the Jack the Ripper pub (till 1975 and since 1988 known as Ten Bells), with Women Against Violence Against Women and Action Against the Ripper Centenary leading the way. What made people really notice the women who were murdered in 1888 was the re-emergence of the photographs of four of them: Mary Ann Nichols, Annie Chapman, Elizabeth Stride, and Mary Kelly (Begg and Bennett 2013, pp. 254-58). Even Madame Tussaud's decided to include a Ripper tableau in an 'eat the cake and have the cake' manner-adhering to its principle of exhibiting true to life figures, they displayed

a reconstruction of a dark, narrow cobbled Victorian street, a sinister alley where the effigy of prostitute Mary Kelly, last victim of Jack the Ripper, leans waiting for custom at the door of her sordid room. In a dim passage the body of Catherine Eddowes lies bloody and mutilated by the invisible Ripper, while patrons drinking in the Ten Bells are disturbed by the sound of screams and running feet. (Pauline Chapman qtd in Woods and Baddeley 2009, p. 170).

While this caused some concern among the Women Against Violence Against Women (Woods and Baddeley 2009, p. 170), it was the 1993 London Dungeon's graphic waxworks forming part of the 'Jack the Ripper Experience' that drew the attention of the Campaign Against Pornography (Begg and Bennett 2013, p. 259). When the Jack the Ripper Museum opened in 2015, it followed the Tussaud's and not the Dungeon's lead. Pictures on its website suggest a possibility of 'meeting' the killer there, yet the display does not include his wax representation. The three figures depicted there are Inspector Abberline in the third-floor recreation of a police station, and PC Watkins finding the body of Catherine Eddowes in the first-floor tableau set in Mitre Square. Even though the scene is not an accurate representation of the state Eddowes was found in, it may be said to correct the mistakes of the past when the sensationalism and cheap thrill of seeing a colourful wax simulacrum, instead of a black and white illustration or reading a description of it in a paper, stood in the way of decency and respect due for the deceased.

Three months before the Jack the Ripper Museum opened, the second season of the mashup TV series Penny Dreadful (2014-2016) premiered. In its first episode, 'Fresh Hell' (2015), the Creature subplot takes the viewers to Putney's Family Waxworks. ${ }^{2}$ It is open every day, and offers historical, comical, and tragical tableaus. Its chamber of horror is labelled The Chambers of Grotesque and Gore, and is being updated with the proprietor's 'new gimmick-my Chambers of Crime ... Homicide scenes plucked from the headlines and recreated here in the most minute detail', his pride and joy. The first of its exhibits to be seen is depicted with his back to the viewer, but there is no mistaking that

2 The series not only is a mashup of various Victorian villainous characters, but also a reworking referencing other works of popular culture. As far as the theme of this article is concerned, the Creature's entering waxworks may be read as a far echo of the Poet from Leni's Waxwork, who also visited it not out of curiosity, but after noticing a job advertisement. His very presence there and confinement to the basement may be an echo of Karkov, a handicapped man (who is even called by some 'a creature') from Fenady's Terror in the Wax Museum. 
top hat, cape, and long bloody knife in his hand; there is also a victim, rather strangely posed for the onlookers' convenience. Mr Putney places his hand on the figure's shoulder and introduces him saying 'Here's old Jack himself', re-establishing the Ripper as the waxworks superstar and reintroducing the special relationship between the proprietor and the exhibit known from Roberts's short story, The Twilight Zone episode, and Terror in the Wax Museum. The strangely posed victim is said to be Annie Chapman: 'What we couldn't discover, we invented, of course. No one will know the difference. You tell the public a thing is real, it is.' Thus, again the status of reality is being questioned, and it is its hyperreal version that holds more appeal to the consumers of the 1888 serial killer narrative. 'Old Jack' was referenced in the first two episodes of the series, 'Night Work' and 'Séance' (2014), set in September 1891, with the press wondering whether he was behind the latest atrocious murders. In the waxworks context, his figure is one of the incentives to visit the exhibition, as suggested by the advertisement at the entrance: 'Coming soon/London's monstrous crimes/brought to life/Jack the Ripper/The Brixton Poisoner/The Mariner's Inn Massacre'. But as the series neo-Victorian voice comes to the fore, the real monsters turn out to be the Putneys themselves.

Mr Putney's careless approach to facts-or rather the medium-specific focus on simulation-is, to some extent, repeated in the latest addition to the waxwork motif: The Wax House: Jack the Ripper (2018), a Virtual Reality game. The difference between the setting of the 1992 Waxworks computer game is that this wax museum is not a collection of random scary rooms, but a place dedicated to the five canonical victims of Jack the Ripper. A voiceover in the game's trailer informs that 'Nobody is saying things happened exactly this way, but I never let facts get in the way of a good story.' The similarity to almost any game of the kind is the objective to solve certain puzzles and find clues leading to the answer to the thirteen-decade-old question: who was Jack the Ripper? His wax representation is placed in the tableaus with the victims, with particular scenes designed to recreate the five murder scenes; interestingly, a sixth one is added with only the killer's figure there. Mary Kelly's room does not look like the interior of 13 Miller's Court, other tableaus may also misrepresent crime scenes, but the dark corridors and dead ends of the museum introduce the proper mood. What also makes this game stand out from other waxworks depicted on screen is that the victims, or their ghosts, appear: they talk, sing, and move. They are given voice, denied to them by curators and creators of wax museums thus far.

The current discussion was started with 1888 waxworks and continued with twenty- and twenty-first-century texts encompassing various media: a novel and short story, films and TV series, computer and virtual reality games, museum exhibitions. This April brought an additional entry to this list-a radio dramatization of Mark Lawson's The Deletion Committee (Lawson 2018), a text reflecting on recent changes in social discourse on women, with social media taking over the debate led by the \#MeToo and \#TimesUp movements. The eponymous committee of Oliver's Waxwork World meets to select waxworks exhibits of (mostly) men who have recently been criticised for their (mostly) sexual transgressions. Gallery by gallery-Corridor of Power, Hollywood Hall of Fame, Sporting Heroes, Creative Geniuses-two women and two men vote whether to delete or display a given figure. No names are given, only numbers, but the transgressions described clearly point to well-known politicians, captains of industry, celebrities. It is when a well-known second-wave feminist's fate is about to be sealed that the selection process starts being questioned. The Chamber of Horrors waxworks, however, are safe; even Jack the Ripper.

Visual depictions of the Whitechapel killer aptly illustrate Jean Baudrillard's concept of simulacra, with his wax likenesses being especially telling, highlighting the absence of the original and bearing no relation to reality. Equipped with stereotypical Ripper-esque signifiers, they 'substitut[e] signs of the real for the real itself' (Baudrillard [1981] 1988, p. 167). Whether exhibited on his own or together with one of the victims, the Ripper's wax tableaus represent scenes taken out of the context and original setting, accommodated to cater to the tastes of contemporary audiences. In 1888, when Londoners were eagerly following the instalments in the Ripper series of murders, their only evident clue was the bodies of the victims. Mutilated by the killer, dissected by the doctors, and further anatomised by the press, 
they were offered to a public hungry for sensation in the form of wax exhibits. Such representation brought about anonymity, as they no longer were Mary Ann Nichols, Annie Chapman, Elizabeth Stride, Catherine Eddowes, or Mary Kelly, but the victims of the Ripper; their disrepute as prostitutes contributed to their marginalisation. Anonymity is also the defining characteristic of their killer which, paradoxically, turned him into a celebrity-notorious, infamous, but instantly recognisable.

Waxen representations of Jack and his victims capitalised on the discrepancies between them: the growing fame of the perpetrator and the lessening importance of the victims were informed by class and gender issues. The latter's initial absence in the wax tableaus represented in popular culture-Waxworks (1924), ' . . said Jack the Ripper' (1957), 'The New Exhibit' (1963), Terror in the Wax Museum (1973) - reflects the significance of the killer as a character in his own right. Their later appearance as clues as to the identity of the figure of the killer-'House of Max' (1970), Waxwork (1998), Waxwork II: Lost in Time (1992), Waxworks (1992), Penny Dreadful (2015, Season 2)-indicates the continuous marginalisation, stereotyping, and even trivialisation of the victims. Unlike their underprivileged real-life counterparts, the screen victims are depicted as more deserving of the interest of the Ripper as the 'gent' /'toff': better dressed and made-up, these wax (and usually animated) figures create seemingly more visually pleasant tableaus-seemingly, since they remain his passive prey. It is The Wax House: Jack the Ripper (2018) that, apart from fairly similar depictions, finally gives them some voice as well. It may be only for the sake of solving the Ripper puzzle, but nevertheless, it may suggest that the waxwork theme has started to catch up with other neo-Victorian representations. In wax tableaus displayed in museums it is the killer who is absent, but the shift in attitude towards the perpetrator and the victim can also be traced. Whereas Madame Tussaud's 1980 'Ripper street' exhibits the mutilated body of Catherine Eddowes and the transgressive body of Mary Kelly awaiting her client, containing an element of the 'male gaze' (Walkowitz 1992, pp. 1-5), the Jack the Ripper Museum displays a police officer discovering the dead (but apparently not mutilated) body of Catherine Eddowes, signalling readiness to catch and punish the murderer.

The Whitechapel killer became Jack the Ripper, an almost mythical creation, and as such has been experiencing an extremely rich afterlife in popular culture. When reimagined in a wax from, however, he seems to share the fate of his victims and becomes one of the means of attracting contemporary audience's attention. In a very postmodern fashion, it is only his image that came to matter, an image that, being a simulacrum, does not, and cannot, reflect reality. Though in each case the wax figure of Jack the Ripper has a face and may be said to be based on a person, the overwhelming majority of the narratives discussed here do not revolve around the identity of the Whitechapel killer. He appears as one of the well-known (possibly best-known, but still one of many) killers or evildoers, a representative of the late nineteenth century, and testimony to our morbid fascination with the Victorian art of murder.

Conflicts of Interest: The author declares no conflict of interest.

\section{References}

Aliffe, Andy. 2002. Jack 'n Wax. Available online: http://www.casebook.org/dissertations/aliffe-wax.html (accessed on 15 April 2018).

Arthur, Robert. 1973. ... said Jack the Ripper. In Alfred Hitchcock Presents: 16 Skeletons from My Closet. New York: Dell Publishing Co., Inc., pp. 89-102. First published 1957.

Baudrillard, Jean. 1988. Symbolic Exchange and Death. In Selected Writings. Edited and Introduced by Mark Poster. Stanford: Stanford University Press, pp. 119-48. First published 1976.

Baudrillard, Jean. 1988. Simulacra and Simulations. In Selected Writings. Edited and Introduced by Mark Poster. Stanford: Stanford University Press, pp. 166-84. First published 1981.

Begg, Paul, and John Bennett. 2013. The Complete and Essential Jack the Ripper. London: Penguin Books.

Carnac, James. 2012. The Autobiography of Jack the Ripper. London: Corgi Books.

Coville, Gary, and Patrick Lucanio. 2008. Jack the Ripper. His Life and Crimes in Popular Entertainment. Jefferson and London: McFarland \& Company, Inc., Publishers. First published 1999. 
Curtis, L. Perry, Jr. 2001. Jack the Ripper and the London Press. New Haven and London: Yale University Press.

Davies, Helen. 2015. Neo-Victorian Freakery. The Cultural Afterlife of the Victorian Freak Show. Basingstoke: Palgrave Macmillan.

Eisner, Lotte H. 2011. Ekran demoniczny [L'Ecran démoniaque]. Translated by Konrad Eberhardt. Gdańsk: Słowo/Obraz Terytoria. First published 1974.

Flanders, Judith. 2011. The Invention of Murder. How the Victorians Revelled in Death and Detection and Created Modern Crime. London: Harper Press.

Haddon, Cole, and M. S. Corley. 2012. The Strange Case of Mr. Hyde. Milwaukie: Dark Horse Books.

Hawley, Mike. 2013. Whitechapel's Wax Chamber of Horrors, 1888. Ripperologist 130: 18-25.

House of Max. 1970. Get Smart. Created by Mel Brooks. New York: CBS, Part 1 and Part 2.

Jones, Mark. 2017. Jack the Representation. In Neo-Victorian Villains. Adaptations and Transformations in Popular Culture. Edited by Benjamin Poore. Leiden and Boston: Brill Rodopi, pp. 161-79.

Laughey, Dan. 2013. Ripper. In Barthes' 'Mythologies' Today. Readings of Contemporary Culture. Edited by Pete Bennett and Julian McDougall. New York and London: Routledge. Taylor \& Francis Group, pp. 94-95.

Lawson, Mark. 2018. The Deletion Committee. Directed by Eoin O'Callaghan. London: Big Fish, BBC Radio 4, Aired on 13 April 2018.

Lowndes, Marie Belloc. 2015. The Lodger. Harpenden: Gaslight Crime. First published in 1913.

Maier, Sarah E. 2012. Chasing the Dragon: Bangtails, Toffs, Jack and Johnny in Neo-Victorian Fiction. In NeoVictorian Gothic. Horror, Violence and Degeneration in the Re-Imagined Nineteenth Century. Edited by Marie-Louise Kohlke and Christian Gutleben. Amsterdam and New York: Rodopi, pp. 197-220.

Man in the Attic. 1953. Directed by Hugo Fregonese. Washington: Panoramic Productions, Leonard Goldstein.

McFarlane's Monsters series 3: Six Faces of Madness. 2004. Available online: http:/ / www.starstore.com/acatalog/ Starstore_Catalogue_McFarlane_s_Monsters_series_3_Six_Faces_of_Madness_3202.html (accessed on 15 April 2018).

Meikle, Denis. 2002. Jack the Ripper. The Murders and the Movies. London: Reynolds \& Hearn Ltd.

Penny Dreadful. 2014-2016. Created by John Logan. New York: Showtime, Seasons 1 and 2.

Schmid, David. 2006. Natural Born Celebrities: Serial Killers in American Culture. Chicago: University of Chicago Press.

Smith, Clare. 2016. Jack the Ripper in Film and Culture. Top Hat, Gladstone Bag and Fog. London: Palgrave Macmillan. Terror in the Wax Museum. 1973. Directed by Georg Fenady. USA: Bing Crosby Productions.

The New Exhibit. 1963. Twilight Zone. Created by Charles Beaumont and Rod Serling. New York: CBS, Season 4 , Episode 13.

The Wax House: Jack the Ripper. 2018. Simi Valley: Hollow Studios, Inc.

Walkowitz, Judith R. 1992. City of Dreadful Delight. Narratives of Sexual Danger in Late-Victorian London. Chicago: The University of Chicago Press.

Waxwork. 1998. Directed by Anthony Hickox. West Germany and Stamford: Palla, Vestron Pictures, HB Filmrullen. Waxwork II: Lost in Time. 1992. Directed by Anthony Hickox. East Fremantle: Electric Pictures.

Waxwork. n.dat. In Oxford Dictionaries. Available online: https:/ / en.oxforddictionaries.com/definition/waxwork (accessed on 21 April 2018).

Waxworks [Das Wachsfigurenkabinett]. 1924. Directed by Paul Leni. Germany: Neptune-Film A.G..

Waxworks. 1992. Designed by Michael Woodroffe, Alan Bridgman and Simon Woodroffe. San Jose: Accolade Inc., $\mathrm{n} / \mathrm{a}$ : Horror Soft Ltd.

Woods, Paul, and Gavin Baddeley. 2009. Saucy Jack. The Elusive Ripper. Chatham: Ian Allan Publishing.

Worsley, Lucy. 2014. A Very British Murder. The Curious Story of How Crime Was Turned into Art. London: BBC Books. First published 2013.

(C) 2018 by the author. Licensee MDPI, Basel, Switzerland. This article is an open access article distributed under the terms and conditions of the Creative Commons Attribution (CC BY) license (http:// creativecommons.org/licenses/by/4.0/). 